\title{
Processos de formação continuada: alinhando práticas e construindo saberes na Educação Física escolar
}

\section{RESUMO}

Processos de formação continuada: alinhando práticas e construindo saberes na Educação Física escolar

Resumo: Os processos de formação continuada foram intensificados nos anos de 2018/2019 no município do Rio Grande/RS, com a finalidade de atender à legislação vigente. $\mathrm{O}$ presente estudo objetivou compreender a percepção de professores de Educação Física sobre sua participação nos processos formativos propostos e as contribuições desses processos para sua prática pedagógica. Trata-se de uma pesquisa descritiva, de caráter qualitativo, que utilizou um questionário autoaplicado como instrumento para coleta de dados. A partir da análise de conteúdo, as categorias emergentes revelaram que participar dos processos formativos é uma oportunidade de compartilhamento e troca de experiências, possibilitando a inovação através da busca por novos conteúdos e metodologias, de modo a qualificar a sua prática pedagógica, além de ser um espaço propício para o exercício da prática reflexiva, impulsionando as adaptações necessárias aos diferentes contextos.
Leontine Lima dos Santos

Doutora em Educação Física

Universidade Federal de Pelotas - UFPel, Escola Superior de Educação Física, Pelotas,

Brasil

leozinhaesef@hotmail.com

(1) https://orcid.org/0000-0002-9686-2339

Fabiana Celente Montiel

Doutora em Educação Física Instituto Federal de Educação, Ciência e Tecnologia Sul-rio-grandense - IFSul / Campus Pelotas, Pelotas, Brasil

fabianamontiel@ifsul.edu.br

https://orcid.org/0000-0002-9921-6703

Mariângela da Rosa Afonso Doutora em Educação

Universidade Federal de Pelotas - UFPel, Escola Superior de Educação Física, Pelotas,

Brasil

mrafonso.ufpel@gmail.com

https://orcid.org/0000-0002-8853-719X

PALAVRAS-CHAVE: Formação continuada;

Educação física escolar; Prática pedagógica 


\title{
Continuing education processes: aligning practices and building knowledge in school Physical Education
}

\begin{abstract}
Continuing education processes were intensified in 2018/2019 in Rio Grande/RS to comply with current legislation. The present study aimed to understand the perception of Physical Education teachers on their participation in the proposed formative processes as well as contributions of such processes to their pedagogical practice. It is a descriptive qualitative study, which used a self-applied questionnaire as an instrument for data collection. Content analysis permeated the organization, the understanding as well as pointed out the developed categories. The teachers signal that participating in formative processes is an opportunity for sharing and exchanging experiences, which enables innovation through the search for new content and methodologies in order to qualify their pedagogical practice, in addition to being a conducive space for the exercise of reflexive practice, promoting the necessary adaptations to different contexts.
\end{abstract}

KEYWORDS: Continuing education; School physical education; Pedagogical practice

\section{Procesos de formación continua: alineando prácticas y construyendo saberes en la Educación Física escolar}

\section{RESUMEN}

Los procesos de formación continua fueron intensificados en los años 2018/2019 en el municipio de Rio Grande/RS para atender a la legislación vigente. El presente estudio tuvo como objetivo comprender la percepción de los profesores de Educación Física sobre su participación en los procesos formativos propuestos y las contribuciones de los procesos a la práctica pedagógica. Se trata de una investigación cualitativa descriptiva, la cual utilizó una encuesta autoaplicada como instrumento para colecta de datos. El análisis de contenido permeó la organización, el entendimiento y apuntó las categorías desarrolladas. Los profesores señalan que participar de los procesos formativos es una oportunidad de compartir y cambiar experiencias, que posibilita la innovación a través de la búsqueda por nuevos contenidos y metodologías de modo a cualificar a su práctica pedagógica, además de ser un espacio propicio para el ejercicio de la práctica reflexiva, impulsando las adaptaciones necesarias a los diferentes contextos.

PALABRAS-CLAVE: Formación continua; Educación física escolar; Práctica pedagógica 


\section{INTRODUÇÃO}

Os marcos legais que amparam a educação brasileira sustentam a realização de processos formativos, de responsabilidade das instituições de ensino superior, como previsto no inciso III do artigo 63 da Lei de Diretrizes e Bases da Educação Nacional - LDBEN (BRASIL, 1996). Tais processos formativos têm como foco a realização de programas de educação continuada para os profissionais da educação dos diversos níveis de ensino, além dos processos de aperfeiçoamento profissional continuado a serem realizados pelos sistemas de ensino, como aponta o inciso II do artigo 67 da LDBEN, os quais possibilitam, inclusive, licenciamento periódico remunerado para esse fim (BRASIL, 1996).

Ao transpor o que a legislação apresenta para a realidade concreta, a formação continuada implica uma articulação entre os saberes docentes, as competências profissionais e a prática pedagógica dos professores. De acordo com Azevedo et al. (2010), esses três elementos, de forma articulada, constituem a formação e a ação docentes, admitindo o entendimento e a experiência da formação continuada como um possível espaço para a reavaliação da prática docente pelos professores, possibilitando, dessa forma, "fundar-se como um ambiente que possibilite a construção de diferentes saberes, de repensar e refazer a prática do professor, reorganizando suas competências e produzindo novos conhecimentos" (AZEVEDO et al., 2010, p.245). De modo análogo, Silva et al. (2020) reforçam a contribuição da formação continuada para a qualificação da pratica pedagógica dos professores de Educação Física (EF) da educação básica.

A formação continuada, para Rossi e Hunger (2012a), tem suas raízes na articulação dialética entre os saberes experienciais dos professores e os fundamentos teóricos utilizados para tal. Dessa forma, "deve ter suas bases nas vivências dos professores no cotidiano escolar, valorizando os saberes da experiência, sem, contudo, desvalorizar a importância das construções teóricas" (ROSSI; HUNGER, 2012a, p.927). Alguns estudos constataram que formações que propõem espaços para construções coletivas se mostraram propícias para a emancipação do professorado, tirando o foco da instrumentalização e reafirmando a corresponsabilidade de professores, pesquisadores, gestores e outros atores educacionais e sociais para alicerçar projetos e ações educacionais integradas. (SILVA; PACCA, 2011; ROSSI, 2013a).

Considerando os desdobramentos da formação continuada na prática pedagógica de professores de EF, Azevedo et al. (2010) apontam que os processos formativos deverão ter a pretensão de atender às demandas específicas da área, com base no contexto escolar, tendo a prática pedagógica como objeto central da proposição, possibilitando ao docente o reconhecimento de sua produtividade, na experiência de sua própria ação docente. 
Colaborando com as ideias já sinalizadas, Bagatini e Souza (2019) entendem a formação continuada como um espaço de relação entre teoria e prática, diálogo, reflexão, reavaliação do fazer pedagógico. Outros autores reforçam a importância da formação continuada, reafirmando ser a troca de experiências um elemento fundamental para o desenvolvimento da autonomia do professor, reforçada a partir do trabalho coletivo (SILVA; PACCA, 2011). Nesse sentido, o presente estudo objetivou compreender a percepção dos professores de Educação Física da rede municipal do Rio Grande sobre a sua participação nos processos formativos propostos e as contribuições desses processos para sua prática pedagógica.

No intuito de situar o estudo realizado, trazemos alguns elementos do contexto investigado, buscando resgatar as ações e estratégias utilizadas pela Secretaria de Município da Educação (SMEd) do Rio Grande, no estado do Rio Grande do Sul (RS), através de um trabalho coletivo com as gestões escolares e em parceria com instituições públicas e privadas, no fomento de processos formativos voltados à construção de um documento orientador curricular local, o qual levasse em consideração a Base Nacional Comum Curricular (BNCC), mas que buscasse o entendimento das dinâmicas realizadas para além dela.

\section{ESCOLHAS METODOLÓGICAS E CAMINHOS PERCORRIDOS}

Os contornos metodológicos assumidos aproximam-se das pesquisas de caráter descritivo com viés qualitativo, as quais, segundo Gil (2008), apresentam como característica a descrição de determinadas populações ou fenômenos. O estudo foi aprovado pelo Comitê de Ética em Pesquisa da Escola Superior de Educação Física da Universidade Federal de Pelotas/RS, através do parecer $\mathrm{n}^{\mathrm{o}} 3.401 .631$.

A primeira aproximação com o contexto investigado foi a busca documental. De acordo com o mesmo Gil (2008), a pesquisa documental, em termos de seus procedimentos, assemelha-se à pesquisa bibliográfica. Entretanto, dela se diferencia quanto à natureza das fontes consultadas, pois utiliza materiais que ainda não receberam tratamento analítico, ou passaram apenas por um tratamento inicial. No caso da presente investigação, foi realizada uma visitação aos relatórios de gestão da SMEd e aos Planos de Ação ${ }^{1}$ (PA) das escolas municipais, dos anos de 2018 e 2019, disponibilizados pela Superintendência de Gestão Pedagógica da SMEd. A busca de documentos

\footnotetext{
${ }^{1}$ Instrumento utilizado pelas escolas da rede municipal do Rio Grande para organizar seus processos formativos direcionados às suas necessidades e contextos.
} 
referentes às formações que permitissem explorar, de forma sistemática, as estratégias de ação adotadas, foi mediada pela aproximação de uma das pesquisadoras com a equipe gestora da SMEd.

O processo de definição dos sujeitos da pesquisa se deu a partir dos 85 professores de Educação Física (EF) que compõem o quadro efetivo da Prefeitura Municipal do Rio Grande, os quais participaram dos processos formativos oferecidos pela SMEd ou daqueles oferecidos por instituições de ensino parceiras, entre os anos de 2018 e 2019. Foram excluídos do estudo sete professores que não se encontravam em efetiva atuação na escola no período de coleta dos dados. Além disso, tivemos a recusa de 20 professores, dos quais 12 atuavam diretamente com EFE, um atuava com Educação Física em Escola Especial (EFEE), dois na Escola de Iniciação Esportiva (EIE), três estavam em cargo de direção ou vice-direção escolar e outros três professores que, na oportunidade, estavam em readaptação de função. Ao final do processo de definição dos sujeitos da pesquisa, conforme mostra a Figura 1, obtivemos o retorno de 58 professores que responderam aos questionários, dos quais se originaram os resultados a serem apresentados (Figura 1).

Figura 1 - Critérios de definição dos sujeitos da pesquisa

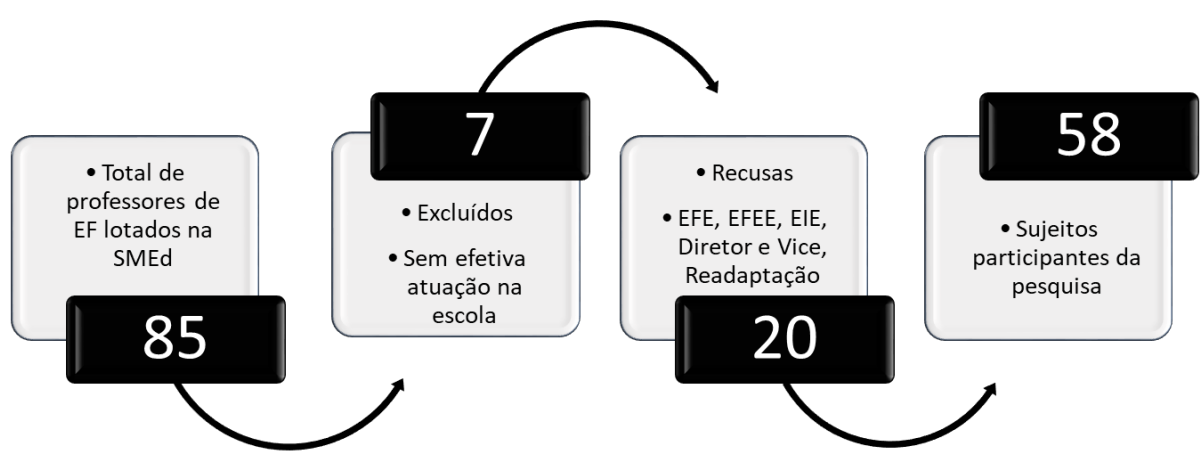

Fonte: Elaborada pelas autoras, 2020.

Para a coleta de dados foi enviado por e-mail e WhatsApp um questionário autoaplicado, via formulário Google, contendo questões abertas e fechadas, referentes ao perfil profissional e sobre formação continuada. O questionário ficou aberto durante o segundo semestre de 2019 e nesse período foram realizadas, no máximo, cinco tentativas de contato entre o pesquisador e os participantes, com o intuito de estimular o professor a responder ao questionário e a participar do estudo. Os participantes aceitaram participar da pesquisa através do Termo de Consentimento Livre e Esclarecido, enviado junto ao questionário, autorizando a utilização dos dados na pesquisa.

O diário de campo foi o instrumento utilizado para registrar as informações pertinentes ao cotidiano dos espaços formativos vivenciados por uma das pesquisadoras. Vale ressaltar que o diário de campo, segundo Falkembach (1987), consiste num instrumento destinado à anotação das 
observações de fatos concretos, fenômenos sociais, acontecimentos, relações verificadas, experiências, reflexões e comentários do investigador.

A análise de dados foi realizada na perspectiva de Bardin (2016), com base nos elementos que compõem a análise de conteúdo. O início se deu com a pré-análise realizada a partir da leitura flutuante dos questionários, o que levou a definição do corpus. Na sequência, com a exploração do material, foram sinalizadas as unidades de registros, que suscitaram ideias e temas comuns em todos os textos analisados. Já o tratamento dos resultados se deu a partir do agrupamento, por frequência e sentido, o que resultou em três categorias: compartilhamento e troca de experiências; inovação e qualificação da prática; e reflexão para a construção.

\section{RESULTADOS E DISCUSSÃO}

As estratégias e ações apresentadas na sequência foram resgatadas tanto dos documentos de registros da SMEd como através da participação efetiva de uma das pesquisadoras enquanto Assessora Pedagógica da EF, dessa instituição. Cabe ressaltar ainda que, em determinados momentos, o diário de campo capturou elementos importantes para o resgate das especificidades desse momento.

Os resultados do estudo foram organizados em eixos investigativos: o $1^{\mathrm{o}}$ eixo desvela os processos formativos realizados no município do Rio Grande entre os anos de 2018 e 2019; o $2^{\circ}$ eixo apresenta a caracterização dos professores investigados e sua adesão a esses processos formativos; e o $3^{\circ}$ eixo traz a percepção dos professores sobre a participação nos processos formativos e as contribuições desses processos para sua prática pedagógica.

\section{Desvelando os processos formativos da SMEd do Rio Grande}

De forma geral, o movimento formativo no município do Rio Grande teve dois focos: o primeiro, com ações propostas pela SMEd através de um congresso, um fórum e encontros por áreas do conhecimento; o segundo, realizado nas escolas, com temáticas condizentes com a realidade local e discutidas a partir das necessidades e do contexto de cada uma das unidades escolares, como podemos observar na Figura 2. 
Figura 2 - Apresentação do processo de formação continuada fomentado no Rio Grande

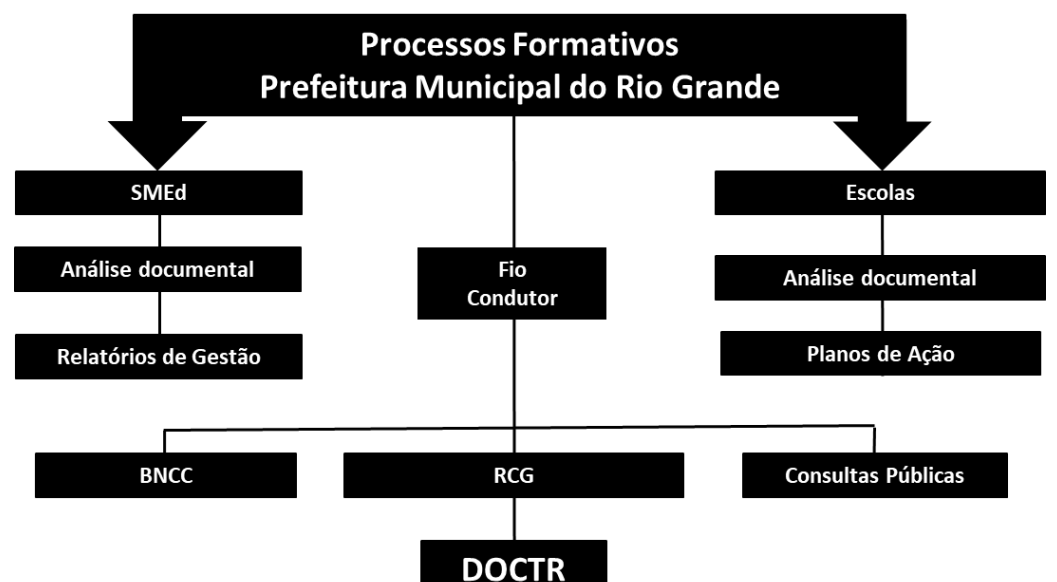

Fonte: Elaborada pelas autoras, 2020.

Os momentos formativos nesse período tiveram como fio condutor ações propositivas, de modo a provocar os professores a conhecer a BNCC e o Referencial Curricular Gaúcho - RCG (RS, 2018), refletindo sobre as suas práticas pedagógicas e a relação com o que está disposto nos documentos normativos, no sentido de pensar de que forma as ações que já desenvolvem nas aulas de EF se relacionam com as competências e habilidades presentes na BCNN e no RCG. O objetivo desse movimento foi valorizar a prática cotidiana dos professores e ampliar suas potencialidades, de modo a inserir no Documento Orientador do Território Rio-grandino ${ }^{2}$ (DOCTR) o que já realizam de positivo no cotidiano escolar.

No intuito de conhecer o processo formativo desenvolvido nesses dois anos, foram analisados os três relatórios de gestão referentes às ações realizadas pela SMEd através do Núcleo de Educação Infantil, do Núcleo dos Anos Iniciais e do Núcleo dos Anos Finais, cujas propostas formativas contemplam, diretamente, os professores de EF. Além disso, foi realizado um levantamento das principais temáticas abordadas nas formações escolares, a partir dos PA das escolas que possuem profissionais de EF em seu quadro de professores.

Os relatórios de gestão do ano de 2018 revelaram que os professores de EF tiveram a oportunidade de participar de três momentos formativos, contando com uma parceria pública da Fundação de Articulação e Desenvolvimento de Políticas Públicas para Pessoas com Deficiência e com Altas Habilidades no Rio Grande do Sul (FADERS). Desses, destaca-se o $8^{\circ}$ Congresso

\footnotetext{
${ }^{2}$ Documento próprio, do território do Rio Grande, que objetiva orientar as escolas da rede pública e privada do município, considerando as características peculiares da região. A sua construção foi orientada pela Resolução CNE/CP No $^{\circ}$ de 20 de dezembro de 2017 e pela Resolução do CEE/RS n n 345, de 12 de dezembro de 2018.
} 
Municipal de Educação (COMED) intitulado Escola ComVida: Entrelaçando Saberes na Construção do Currículo, proposto aos profissionais da educação, responsáveis e estudantes, o qual oportunizou a reflexão sobre o processo de reconstrução do currículo nas escolas. Além desse, houve também o encontro formativo realizado em parceria com o Núcleo de Diversidade e Inclusão da SMEd, sobre a "Inclusão na EFE", o qual propôs a reflexão sobre essa temática. Finalizando o ano, ocorreu ainda o Fórum temático do Paradesporto: promovendo movimento e inclusão, ação realizada em parceria com a FADERS, que teve como foco a inclusão de alunos com necessidades educativas específicas e possibilitou reflexões e trocas de experiências referentes a possíveis adaptações a serem realizadas na EFE.

As temáticas que emergiram com uma maior frequência na análise dos 29 PA escolares referentes ao ano de 2018 foram as seguintes: os estudos relativos à BNCC com ênfase nas competências e habilidades dos componentes curriculares; a inclusão dos alunos com deficiência, no que se refere ao processo de formulação das adaptações curriculares; o ensino através de projetos, com vários indicativos de proposições interdisciplinares; as formas de avaliação, desde a construção de pareceres e portfólios ou atribuição de notas.

Os relatórios de gestão de 2019 revelaram que houve a proposição de quatro encontros formativos, sendo que a realização de dois deles teve a parceria do Instituo Esporte e Educação. Esses encontros tiveram como foco a alfabetização motora e o esporte educacional. Outro encontro teve como temática as políticas educacionais, com o intuito de análise dos documentos legais com vistas à (re)construção dos regimentos escolares e do Projeto Político Pedagógico (PPP), reforçando o que foi proposto no COMED e tendo no horizonte a construção do DOCTR. O quarto encontro ocorreu após a divulgação da versão preliminar do DOCTR, com vistas a seu aprimoramento e elaboração da versão final.

O destaque entre as temáticas mais frequentes nos 27 PA analisados, referentes ao ano de 2019, foi a revisitação aos documentos escolares (regimentos e PPP), através do fortalecimento das relações entre escola e comunidade, escola e aluno, escola e profissionais da educação. Outro ponto presente foi o entrelaçamento dos conhecimentos a serem construídos a partir dos documentos oficiais - BNCC e RCG -, de modo a impulsionar a participação dos professores na elaboração do DOCTR, através das reflexões e discussões a partir desses documentos, tanto durante os encontros formativos nas escolas quanto na participação nas consultas públicas.

No que se refere à construção do DOCTR, esteve aberta na página da SMEd, no período de 15 de abril a 20 de maio de 2019, uma consulta púbica que objetivou coletar contribuições da comunidade escolar. Nesse movimento, os professores, a partir das discussões propostas nos encontros formativos realizados nas escolas, tiveram a oportunidade de postar suas contribuições, 
com foco nas habilidades a serem desenvolvidas com os estudantes, referentes às características locais e regionais.

Após a compilação das sugestões oriundas da primeira consulta pública, foi divulgada e disponibilizada às comunidades escolares a versão preliminar do documento, a fim de que os profissionais da educação tivessem a oportunidade de contribuir na qualificação do mesmo, fortalecendo o processo democrático e participativo. Nesse momento, foi lançada a proposta da SMEd de realizar um encontro formativo por componente curricular, para fomentar as reflexões e discussões entre os pares. Esse quarto e último encontro formativo, direcionado aos professores de EF, propiciou a leitura, a reflexão e a reconstrução, de forma coletiva, das habilidades a serem abordadas no documento. $\mathrm{Na}$ oportunidade, os professores relataram a satisfação em fazer parte daquele momento formativo, oportunidade em que puderam conversar e trocar experiências com os seus pares.

Percebemos que tanto os processos formativos propostos pela SMEd quanto aqueles fomentados nas instituições escolares objetivaram a apropriação dos documentos oficiais pelos professores, além de refletir sobre suas práticas pedagógicas e projetá-las de forma efetiva na construção do DOCTR.

\section{Caracterização dos professores e análise da adesão aos processos formativos}

Objetivando a apresentação do perfil dos professores participantes do estudo foi elaborada a Tabela 1, a seguir, com os principais elementos que caracterizam esses professores.

Tabela 1 - Perfil dos professores participantes do estudo.

\begin{tabular}{lcc}
\hline Variável & $\mathbf{N}(\mathbf{5 8})$ & $\mathbf{\%}$ \\
\hline Sexo & & \\
$\quad$ Masculino & 23 & 39,7 \\
$\quad$ Feminino & 35 & 60,3 \\
\hline Idade & & \\
$\quad$ Até 35 anos & 13 & 22,4 \\
$\quad 36-45$ anos & 25 & 43,1 \\
$\quad$ 46 anos ou mais & 20 & 34,5 \\
\hline Local de formação inicial & & \\
$\quad$ Universidade Pública & 51 & 87,9 \\
$\quad$ Universidade Privada & 7 & 12,1 \\
\hline Ano de conclusão da graduação & & \\
$\quad$ Até 1990 & 6 & 10,3 \\
1991-2010 & 40 & 69,0
\end{tabular}




\begin{tabular}{lcc}
$2011-2015$ & 12 & 20,7 \\
\hline Formação Continuada & & \\
Especialização (concluída/em andamento) & 44 & 75,8 \\
Mestrado (concluído/em andamento) & 8 & 13,8 \\
Doutorado (concluído/em andamento) & 3 & 5,2 \\
\hline Tempo de docência vinculada à SMEd & & \\
1 - 4 anos & 13 & 22,4 \\
5 - 9 anos & 17 & 29,4 \\
10 - 19 anos & 14 & 24,1 \\
20 ou mais anos & 14 & 24,1 \\
\hline
\end{tabular}

Fonte: Elaborada pelas autoras, 2020.

Podemos dizer que a maioria dos sujeitos da pesquisa são do sexo feminino $(60,3 \%)$, com mais de 36 anos de idade (77,6\%), tendo cursado a graduação em instituições públicas (87,9\%), concluída entre os anos de 1991 e 2010 (69\%) e que possuem formação continuada em nível de especialização $(75,8 \%)$. No que se refere ao vínculo com a SMEd, chama a atenção que $24,2 \%$ dos professores estão no fim de carreira, possuindo mais de 20 anos de docência, e 22,4\% dos professores estão no início da carreira, com um a quatro anos de docência. Nesse sentido, percebe-se que a maioria dos docentes está atuando na educação básica desse município há, no mínimo, cinco anos, havendo vivenciado os processos de formação continuada propostos.

Para além da garantia de espaços formativos, um ponto a ser considerado é a valorização dada pelo município do Rio Grande aos profissionais de educação, a qual está prevista no inciso IV do artigo 67 da LDBEN. Nesse sentido, a nova redação do plano de carreira, instituído pela Lei $\mathrm{n}^{\circ}$ 7848/2015 (RIO GRANDE, 2015), garante aos professores um acréscimo de 70\%, 80\% e 90\% sobre o vencimento básico inicial para aqueles que possuírem especialização, mestrado e doutorado, respectivamente. Essa valorização estimula os professores a buscarem sua qualificação profissional, o que se explicita no fato de $75,8 \%$ dos professores participantes da pesquisa possuir ou estar concluindo curso de pós-graduação em nível de especialização, 13,8\% ter mestrado concluído e $5,2 \%$ ter doutorado, enquanto apenas $5,2 \%$ dos sujeitos têm apenas graduação. Como apontam Bagatini e Souza (2019), a busca por processos formativos contínuos pode ser vista como uma busca de valorização do professor.

Quando questionados a respeito de seu envolvimento em processos formativos, percebemos, conforme exposto na Tabela 2, que grande parte dos professores responderam que sempre $(32,7 \%)$ ou quase sempre $(53,5 \%)$ participam. Os professores relatam participar das formações propostas pela SMEd $(87,9 \%)$ e pelas escolas onde atuam $(74,1 \%)$, além de trazerem à tona a participação em seminários e congressos propostos por outras instituições, com ênfase naqueles relacionados à área do autismo. Já ao serem questionados se os temas ou oficinas 
oferecidas por essas instituições contribuem para sua atuação profissional, a maioria dos professores respondeu que sempre $(39,7 \%)$ e quase sempre (46,6\%) contribuem. Por outro lado, os professores que raramente $(6,9 \%)$ ou nunca $(3,4 \%)$ se envolvem nos processos formativos e relatam que os temas propostos não dialogam com suas atuações profissionais são aqueles que se encontram afastados das aulas formais de EF, seja por readaptação de função ou por atuarem diretamente com projetos esportivos, direcionando sua prática a modalidades esportivas específicas.

Tabela 2 - Adesão dos professores a processos formativos e contribuição dos temas propostos

\begin{tabular}{lcc}
\hline Variável & $\mathbf{N}(\mathbf{5 8})$ & $\mathbf{\%}$ \\
\hline Adesão a processos formativos & & \\
$\quad$ Sempre & 19 & 32,7 \\
Quase sempre & 31 & 53,5 \\
$\quad$ Raramente & 8 & 13,8 \\
\hline Instituição(ões) que promovem os encontros formativos & & \\
Escola(s) & 43 & 74,1 \\
SMEd & 51 & 87,9 \\
Outras & 9 & 15,6 \\
\hline Contribuição dos temas ou oficinas na atuação profissional & & \\
Sempre & 23 & 39,7 \\
Quase sempre & 27 & 46,6 \\
Raramente & 4 & 6,9 \\
Nunca & 2 & 3,4 \\
Não responderam & 2 & 3,4 \\
\hline
\end{tabular}

Fonte: Elaborada pelas autoras, 2020.

Assim, os dados levantados vão no sentido de corroborar a posição de Azevedo et al. (2010) de que é preciso pautar a formação continuada nos saberes docentes, especialmente na sua materialização na prática pedagógica e nas competências específicas da área. Tais processos tornam-se proeminentes no sentido de ampliar as possibilidades de atuação no campo de trabalho, oferecendo mais espaço às práticas.

\section{Percepção dos professores sobre a participação nos processos formativos e as contribuições na sua prática pedagógica}

A partir do entendimento de como ocorreram os processos formativos no município do Rio Grande, conhecendo a caracterização dos participantes da pesquisa e seu envolvimento nos processos formativos, passaremos à discussão de cada uma das três categorias que emergiram da análise dos questionários no que se refere às contribuições desses processos formativos na prática 
pedagógica dos professores participantes, como segue: compartilhamento e troca de experiências; inovação e qualificação da prática; e reflexão para a construção.

\section{Compartilhamento e troca de experiências}

A primeira categoria que apresentamos, no sentido de compreender as contribuições das formações oferecidas pela SMEd do Rio Grande para a prática pedagógica do professor de EF, é chamada de compartilhamento e trocas de experiências. Começamos por essa, pois verificamos que as contribuições estão amarradas entre si e que uma categoria acaba por puxar a próxima que será apresentada e discutida.

O sujeito $\mathrm{S} 1$, ao referir-se à contribuição da formação continuada na sua prática pedagógica, reforça o quão importante é estar em constante formação, destacando como ponto principal as "trocas que existem entre colegas da área". Essas trocas são fundamentais para o processo de construção do seu fazer pedagógico, pois os professores estão conversando com colegas que vivenciam uma realidade muito próxima da sua. Em estudo realizado por Oliveira (2020, p.134), que desenvolveu um processo formativo coletivo com o grupo de professores, a partir do diálogo e da troca de experiências, foi identificada a ampliação das possibilidades de atuação, além da contribuição positiva na prática pedagógica dos professores envolvidos, a partir do que foi proposto.

Reforçando esse ponto, Godoi e Borges (2019) apontam que a participação dos professores nas formações ofertadas, com objetivo de discutir a implementação curricular da disciplina de EF, permitiu a troca de experiências e a reflexão sobre o currículo, o qual é utilizado como pano de fundo para o planejamento, embora seja adaptável e necessite ser associado a outros recursos e experiências profissionais que constituem as práticas docentes.

Nesse mesmo sentido, o sujeito S4 ressalta a pré-disposição dos professores que participam de uma formação continuada, pois normalmente, pelo simples fato de estarem ali, já demonstram estar dispostos a trocar ideias. Portanto, esse é um momento importante para que o professor aproprie-se de uma ou outra ideia, como relata S4: "sempre aproveito, adaptando ideias à realidade da escola e dos alunos". O sujeito S30 ainda acrescenta que "nas formações podemos compartilhar com os colegas experiências, que sempre agregam na minha prática pedagógica”.

O professor, ao se envolver numa discussão provocada durante o processo formativo, acaba por comparar o trabalho apresentado pelos pares com ações já desenvolvidas por ele, o que, segundo Silva e Pacca (2011), suscita sugestões e exemplos. Dessa forma, surgem ideias e os conhecimentos são (re)construídos. Essa troca com os colegas, principalmente com aqueles da 
mesma área, torna o processo formativo "uma experiência enriquecedora”, como destaca o sujeito S10, pois contribui para a prática diária, agregando novos conhecimentos e experiências compartilhadas. O sujeito S32 acrescenta que "as formações específicas na área de Educação Física nos permitem compartilhar experiências, conhecer as diferentes realidades e apresentar a minha”.

Righ, Marin e Souza (2012), em estudo realizado com professores participantes de uma formação continuada promovida pela Universidade Federal de Santa Maria, constataram que tal participação possibilitou o convívio com os pares e o compartilhamento de experiências referentes à disciplina de EF, agregando novos conhecimentos a partir das diferentes realidades apresentadas. Essas experiências compartilhadas vão desde boas práticas e ideias até angústias e avaliações sobre o que funcionou e o que não funcionou com determinado grupo de alunos. Como sinaliza o sujeito $\mathrm{S} 14$, as formações continuadas, são um momento de "dividir opiniões com colegas" e também uma oportunidade de "compartilhar dificuldades com as turmas". O encontro com os pares, proporcionado pelas formações continuadas, permite que os professores se reconheçam dentro de um coletivo e percebam que muitas de suas dificuldades e problemas também estão presentes nas aulas e nas escolas de outros colegas.

Nesse sentido, os encontros formativos transcendem os conteúdos propostos, sendo apontados como momentos de alívio para os professores participantes, por não se perceberem sozinhos, como podemos visualizar no excerto do estudo realizado por Righ, Marin e Souza (2012, p. 884): "quando nos deparamos com situações-problemas, junto a colegas que já vivenciaram tais momentos, fica mais fácil resolvermos ou então acharmos soluções rápidas”.

As trocas dentro de um processo formativo podem ocorrer tanto entre os colegas presentes quanto entre participantes e formador/es. Quando o professor destaca a "troca de experiências" (S22) como uma das contribuições da formação continuada para a sua prática pedagógica, é preciso considerar todos os agentes que participam desse processo, compreendendo que o compartilhamento está presente entre todos os envolvidos. No que se refere à figura do formador, Borges e Carvalho (2020) apontam-na como fundamental no processo, tendo o papel de promover discussões e mediar proposições para a solução de problemas, de forma coletiva, ressignificando saberes e promovendo a articulação de práticas contextualizadas no chão das escolas, através da troca de experiências proposta nos espaços formativos.

Os conhecimentos adquiridos durante uma formação continuada foram constantemente sinalizados pelos participantes envolvidos, os quais relacionam muito essa aquisição à oportunidade de partilhar vivências, aprendizados e práticas. Esse fato é confirmado no registro do sujeito S24, ao manifestar que "é sempre produtiva a troca de experiências e os novos conhecimentos adquiridos 
nas formações". Corroborando essa ideia, em estudo realizado por Rossi (2013a), os professores associaram a importância das ações formativas à contribuição dos conhecimentos apreendidos para a melhoria da prática pedagógica, pois esses processos proporcionam momentos favoráveis ao compartilhamento de experiências e a possíveis soluções de problemáticas relacionadas ao ensino e à aprendizagem.

É possível perceber esse mesmo ponto no comentário do sujeito S25, quando expõe que a formação continuada "representa importante recurso para atualizações, novos aprendizados $e$ principalmente a troca de experiências entre seus participantes”, enfatizando mais uma vez a troca de experiências como um fator positivo dentro de um processo de formação. Como ressalta o sujeito S33, "a troca de informações e experiências com os colegas é que são muito válidas". Dessa forma, não podemos e não devemos deixar de lado esse importante papel que as formações continuadas apresentam.

No tocante à realização dos processos formativos, vale ressaltar a sua importância enquanto espaço de troca, construção de diferentes aprendizados e solução de problemas, nos quais os participantes buscam partilhar suas experiências práticas. Como afirmam Bagatini e Souza (2019, p.12), “a Formação Continuada também deve possibilitar ao professor a partilha de suas dúvidas mais frequentes com os colegas - pois isso também ajuda na resolução dos problemas -, além de incentivar a possibilidade de diálogo entre a teoria e a prática”.

Por fim, é importante acrescentar que os professores evidenciam que esse partilhar de informações e experiências incide positivamente em sua prática pedagógica, no sentido de mudança, como é reforçado pelo sujeito S50 ao apontar que a formação continuada proporciona um "enriquecimento das aulas, uma troca de experiências que pode possibilitar mudanças na prática e teoria”. As trocas de experiências, vivências, informações, conhecimentos, angústias, desafios e sucessos proporcionados pelas formações continuadas oferecidas aos professores de EF levaram muitos a modificar a sua prática pedagógica, incorporando novos elementos e trazendo uma qualificação para suas aulas, fato esse que será explorado em mais detalhes na próxima categoria.

\section{Inovação e qualificação da prática}

A segunda categoria que abordaremos vai trazer elementos referentes às inovações que as formações continuadas possibilitam, dando suporte para uma qualificação da prática pedagógica do professor, no sentido de proporcionar tanto sua atualização quanto seu aprimoramento. A inovação nas aulas é um dos focos dos professores que buscam os processos de formação continuada. Essa 
inovação proposta a partir das trocas de experiências entre as professoras pode ser verificada nos achados de Rossi (2013a, p.227), quando evidencia que "ocorre um movimento de inovação quando as professoras têm a oportunidade de dividir suas experiências e pesquisas que realizam sobre o ensino e suas próprias práticas".

O sujeito S1 menciona que a partir das formações sempre tenta levar algo novo para as suas aulas e esse mesmo fato é reforçado quando o sujeito S2 relata que "sempre aprendemos algo". Nesse aprendizado está o que de novo é possível o professor incorporar à sua prática, seja um novo conceito, uma nova metodologia ou apenas um novo jogo para desenvolver e trabalhar determinado tema da cultura corporal. A necessidade de frequentar os espaços formativos a fim de buscar inovações para suas práticas cotidianas escolares é sinalizada por Rossi e Hunger (2012b), ao analisarem o grupo de professores que se encontra na fase de serenidade ou desinvestimento na carreira, de modo a superar lacunas referentes ao tempo de atuação.

Nesse sentido, o sujeito S5 refere-se às formações continuadas ressaltando que " $a$ melhor maneira de continuar aprendendo, é unir teoria e prática, confrontando com a realidade do contexto no qual atuo e, consequentemente, aperfeiçoando minhas competências profissionais". A possibilidade de unir teoria e prática destacada pelo docente é fundamental para o processo educativo, quando o professor consegue compreender e visualizar o que está sendo proposto em determinada formação, facilitando uma aplicação posterior em sua prática pedagógica. Em estudo realizado por Silva et al. (2020) destaca-se como positiva a possibilidade de aprofundamento teórico e a constante relação entre teoria e prática. Tais ganhos são possíveis através da periodicidade dos encontros formativos associados aos diferentes temas discutidos relativos aos princípios pedagógicos do esporte educacional presentes na pratica pedagógica dos participantes. Podemos observar essa relação da teoria e da prática na exposição do sujeito S7, ao afirmar que as formações trazem influências positivas, "agregando novidades tanto na prática quanto na teoria”. Os professores de EF possuem uma característica mais prática, pelo fato de trabalhar com uma disciplina que é do movimento, do corpo, do agir, do fazer; é essencial, no entanto, ter clareza sobre toda a teoria que está vinculada a cada movimento, elemento, fundamento, expressão prática dos diversos conteúdos da cultura corporal.

De acordo com o sujeito S6, as formações continuadas contribuem para "a melhoria das aulas", pois acabam por "acrescentar ideias e práticas" (S6). Evidencia-se assim o quão positivos são considerados os processos formativos, em especial quando se vinculam a uma contribuição direta na prática pedagógica. Grande parte dos participantes destacou essa contribuição, que foi referida como "produtiva” (S9), "essencial” (S16), "positiva" (S17), "válida” (S48), "muito boa”, (S56) e tantas outras formas ao longo dos questionários. Como destaca o sujeito S13, as formações 
continuadas "são ótimas, renovam a nossa prática pedagógica". Essa renovação é o que traz a "motivação para o dia a dia" (S35), que faz com que os professores não se acomodem e busquem fazer algo diferente em suas aulas, para os seus alunos, de modo a trazer novas e diversificadas experiências, as quais contribuirão significativamente para o desenvolvimento e a formação do aluno.

O estudo realizado por Rossi (2013a) sinaliza que o envolvimento nos processos de formação continuada facilita o trabalho docente e aponta a necessidade da construção de uma prática em conjunto com os alunos, de forma reflexiva e elaborada por todos os envolvidos no processo educativo. Nesse sentido, participar de práticas de formação possibilita a ampliação do trabalho docente, impulsionando o desenvolvimento dos alunos. O sujeito S8 acrescenta que não só os alunos, mas todas as pessoas, estão “em constante mudança e os jovens ainda mais”, por isso, para esse docente, é "preciso buscar novas fontes, ideias, debates para melhorar a qualidade da aula”. As formações continuadas, como destacam diversos autores, são uma oportunidade para essas buscas, para alcançar essa almejada melhora na qualidade das aulas (ROSSI, 2013a; 2013b; ROSSI; HUNGER, 2012a; 2012b; BAHIA, 2016; OLIVEIRA, 2020; SILVA et al., 2020).

Colaborar com a ressignificação das práticas e assumir posturas mais ousadas e inovadoras são atitudes essenciais dos professores frente ao cenário atual da educação e da formação continuada, como apontam Borges e Carvalho (2020, p.8):

Afinal, não basta escolher e aplicar estratégias pedagógicas de ensino, é necessário estar preparado para intervir nos diversos segmentos das relações humanas, pesquisar e propor soluções para as dificuldades detectadas ao longo do fazer pedagógico e das vivências dos professores e alunos.

Os professores participam tanto de formações específicas da sua área como de formações com conteúdos mais amplos, que envolvem conhecimentos diversos ligados à educação e ao ambiente escolar. Porém, a formação específica de cada disciplina é fundamental, pois, como manifesta o sujeito S14, “contribui para a atualização de conceitos da área”. Então, ao promover uma formação, as secretarias de educação e as escolas devem atentar para que contemplem tanto questões mais gerais quanto mais específicas, direcionadas às diversas áreas do conhecimento que compõem o currículo escolar. Os professores apontam como prioridade, ao participar de processos formativos, a busca por embasamento para trabalhar novos conteúdos e se atualizarem constantemente frente às novidades do campo educacional (ROSSI, 2012a).

A associação de fatores como carga horária estendida, apoio pedagógico da SMEd e diversidade de temas abordados durante o processo de formação contínua foi sinalizada por Silva et al. (2020) como determinante para a verificação de uma prática pedagógica que qualifica o ensino 
do esporte na escola, ressignificando o aprendizado dos professores. Como se refere o sujeito S19, as formações continuadas são muito importantes, pois “ajudam no resultado das aulas". Então, a atenção ao propor uma formação continuada deve estar vinculada ao que o professor deseja, quais suas necessidades, que conhecimentos o professor está procurando. As formações continuadas devem estar vinculadas às demandas do cotidiano escolar, às questões da sala de aula de cada professor e do coletivo como um todo.

Os sujeitos S23, S24, S28, S31 e S32 sinalizam a contribuição dos processos formativos para suas práticas, no sentido de seu aprimoramento, ou seja, como expressa S24, a formação continuada "faz com que tenhamos uma nova visão de como trabalhar a Educação Física". No mesmo sentido, o sujeito S23 relata que "agrega bons valores e conhecimentos", dos quais o professor manifesta que procura "retirar o máximo e reproduzir de alguma forma nas [...] aulas" (S23). Além disso, as formações que abordam questões mais gerais da educação devem ser contempladas, pois, como salienta o sujeito S54, as mesmas são importantes, "tendo em vista que, em diversos momentos nos deparamos com situações com as quais não sabemos como lidar e esses encontros acabam auxiliando no que diz respeito a tais situações problemas".

A participação na formação continuada contribui na constituição da carreira docente. Os professores reconhecem a importância desses momentos e ressaltam as influências para a vida profissional. Rossi (2012b) sinaliza que os interesses dos professores na busca dessa qualificação se modificam em cada fase da carreira, sendo fundamentais para o aprimoramento da prática pedagógica daqueles professores que estão na fase de entrada na carreira. Reforçando esse ponto, os participantes destacam que as formações continuadas acabam por auxiliar na "formulação dos planos de aula e adaptações de conteúdos" (S34), "enquanto recursos de aprendizagem” (S32), além de serem uma forma de "aquisição de novos conhecimentos e metodologias" (S51). O sujeito S36 assim afirma:

\footnotetext{
A formação é importante para o professor se atualizar em sua proposta metodológica. A educação está sempre em transformação, em movimento e nós professores temos a responsabilidade de acompanhar e estar buscando respostas aos novos desafios. A formação continuada tem este papel fundamental para a vida profissional do professor (S36).
}

Evidenciamos a importância da formação continuada para a inovação e a qualificação da prática do professor, porém cabe ressaltar que a mudança em seu fazer pedagógico não se dará de imediato, pois é preciso uma reflexão sobre e a partir de suas aulas para que seja possível uma reorganização, uma reconstrução do que o professor desenvolve no ambiente escolar. As formações continuadas também têm esse propósito de provocar a reflexão dos docentes, de modo a 
valorizarem o que fazem, visualizarem o quanto de práticas positivas está presente nas suas aulas e projetarem novas possibilidades. A reflexão será a base da discussão da próxima categoria.

\section{Reflexão para a construção}

O processo de reflexão é algo que está presente na rotina do professor que, ao planejar, leva em consideração os momentos vivenciados em aula, com seus alunos, para, a partir desse processo reflexivo sobre o que aconteceu, o que foi positivo, o que poderia ser diferente, iniciar um novo planejamento. O processo de formação continuada com acento na inclusão escolar, proposto por Oliveira (2020), partiu das reais necessidades dos professores e, por meio da ação/reflexão/ação, instigou a transformações nos seus fazeres pedagógicos e, consequentemente, em seus planejamentos, como segue:

Desenvolvemos a formação, de forma sistematizada, com base nos anseios, desejos
e nas necessidades formativas dos partícipes, o que possibilitou a ressignificação de
paradigmas já existentes e o olhar mais amplo frente à diversidade que
encontramos nas escolas e na sociedade, buscando estratégias que proporcionassem
vivenciar e refletir sobre determinadas ações em diálogo com a prática, tornando-as
acessíveis a todos os alunos, independentemente de apresentarem ou não alguma
deficiência (OLIVEIRA, 2020, p.134).

Esse repensar a prática diária também foi destacado pelos professores participantes do presente estudo, ao abordarem sobre as contribuições das formações continuadas para sua prática pedagógica. Como sinalizado pelo sujeito S7, os temas abordados a partir dos processos formativos fazem o professor "rever o que está sendo feito no planejamento do trimestre e na atuação em si". A formação continuada provoca esse olhar para si mesmo, para o que o professor está fazendo, para as suas aulas de EF, para o ambiente escolar, para os seus alunos. Sob esse ponto de vista, as intenções dos agentes formadores são fundamentais, intervindo junto à realidade do grupo de professores participantes dos processos formativos, de modo a construir coletivamente as aprendizagens em torno de situações do cotidiano, integrando no processo a prática reflexiva, com o intuito de contribuir para a construção de possibilidades concretas de solução ou de mudanças (ROSSI, 2013a).

As compreensões sobre a formação continuada em exercício, sinalizadas pelos professores de EF no estudo de Bahia (2016, p. 118), aparecem atreladas tanto aos "processos de reflexão e ressignificação da práxis pedagógica permanentemente" quanto ao desenvolvimento profissional promovido por seu envolvimento nos processos formativos. A prática reflexiva, quando aplicada no 
contexto escolar, possibilita que os professores deixem de atuar como meros reprodutores de técnicas, como coloca Rossi e Hunger (2012a, p.928):

[...] que a formação não seja um componente isolado da profissão docente e que se traduza em oportunidades para que o professor transcenda a posição de profissional técnico que implementa prescrições de outros, convertendo-se em um profissional que participe ativa e criticamente no processo de inovação e mudança educacional e social.

O processo reflexivo provocado no professor, a partir de uma temática que está sendo apresentada, uma metodologia que está sendo proposta, uma política educacional que está para ser implementada, como é o caso da BNCC, proporciona-lhe, como expresso pelo sujeito S11, "novas ideias". Essas ideias estão vinculadas aos novos conhecimentos que estão sendo construídos, a partir das discussões e provocações propostas.

O estudo de Oliveira (2020) possibilitou constante reflexão durante a formação continuada colaborativa, a qual propôs vivências que dialogaram com a proposta de EF para todos e propiciou a construção de novos conhecimentos durante o processo, os quais ampliaram o repertório de possibilidades que se somaram à proposta de ensino dos professores. "Foram encontros de trocas intensas e de constantes aprendizagens, que fizeram com que o grupo de professores de EF do município de Ceará-Mirim/RN se tornasse mais fortalecido no espaço formativo e nos espaços escolares" (OLIVEIRA, 2020, p.134).

Nessa mesma direção, o sujeito S15 manifesta que a formação continuada faz o professor “refletir e contextualizar o ensino-aprendizagem”, reforçando, assim, a importância do professor reexaminar os seus processos de ensino e de aprendizagem, de revisitar sua prática pedagógica, acrescentando elementos que contextualizem o que está sendo proposto ao aluno, tornando as aulas de EF significativas, nas quais o aluno compreende a importância para a sua vida do conhecimento que está sendo construído. O sujeito S42 destaca esse mesmo ponto, relatando a "oportunidade para reflexão no meu ensino/aprendizagem”.

A ideia de que o professor, durante o processo formativo, encontra-se em constante aprendizado, o qual refletirá diretamente na sua atuação profissional, é reforçada por Silva e Pacca (2011, p. 34), pois a postura reflexiva do professor tanto no individual quanto no coletivo "possibilita um aprender constante e um planejamento dinâmico que muda ou se aprimora no sentido de atender às necessidades do professor e de seus alunos".

$\mathrm{O}$ sujeito $\mathrm{S} 18$, ao mencionar o processo de reflexão do professor sobre a prática oportunizado pela formação pedagógica, refere-se ao ganho dos alunos e afirma que "as formações pedagógicas proporcionam uma reflexão sobre nossa prática dentro da escola e no final quem sai ganhando são os nossos alunos" (S18). O ganho mencionado pelo professor pode estar relacionado 
tanto à inovação das aulas - discutido na categoria anterior - quanto a aulas que tragam um significado para os alunos, que eles consigam relacionar com o seu cotidiano, contribuindo assim para sua formação integral. Como reforçam Silva et al. (2020, p181), “a escola necessita ser um espaço de produção de conhecimento relevante à vida dos escolares, que promova diferentes domínios cognitivos, afetivos e motores, de modo a buscar uma integralidade do processo formativo".

A “reflexão da prática” (S22), o "repensar a prática” (S58), as “novas ideias” (S11), o "momento de reavaliação" (S45) e outras contribuições nesse mesmo sentido, destacadas pelos sujeitos, são essenciais para o fazer pedagógico. Os momentos formativos são um espaço e um tempo para o professor parar e fazer essa análise de como está a sua prática. Como destaca o sujeito $\mathrm{S} 51$, as formações estimulam "uma reflexão sobre a minha prática pedagógica, procurando melhorar as aulas". Ainda acrescenta que "auxiliam com novas propostas de ensino, contribuindo para a reflexão diária das nossas práticas" (S51).

Nóvoa (1995) sublinha a necessidade da valorização de paradigmas de formação que instiguem professores reflexivos, os quais assumam a responsabilidade por seu próprio desenvolvimento profissional, participando como protagonistas na implementação de políticas educativas. Como manifesta o sujeito $\mathrm{S} 37$, a formação continuada "nos ajuda a rever a nossa prática e incentiva novos desafios" e entre esses desafios, lançados aos professores, está a incorporação da BNCC em nossos currículos, temática contemplada ao longo das propostas formativas promovidas pela SMEd do Rio Grande e muitas vezes nas próprias escolas de cada um dos professores participantes.

As formações continuadas contribuíram para o compartilhamento e as trocas de experiência, para qualificar e inovar as aulas, assim como para os professores refletirem sobre a sua prática pedagógica. $\mathrm{O}$ intuito desses momentos formativos foi provocar os professores a conhecerem e a pensarem sobre a BNCC e o RCG, refletirem sobre as suas práticas pedagógicas e a relação com o que está disposto nesses documentos, no sentido de pensar de que forma o que realizavam em suas aulas de EF se relacionava com as competências e habilidades presentes na BCNN e no RCG, visando valorizar o cotidiano dos professores e contribuir com a inserção de suas práticas positivas no DOCTR que, dessa forma, viria a ser construção coletiva da própria comunidade escolar.

\section{CONSIDERAÇÕES FINAIS}

O presente estudo possibilitou verificar que a maioria dos professores de EF se envolve nos processos formativos propostos tanto pela SMEd quanto pelas instituições escolares onde atuam, 
além de relatarem que os temas e oficinas oferecidos contribuem para a qualificação de sua atuação profissional.

É possível perceber que a participação nos processos formativos é um processo intrínseco ao professor, relacionada à sua predisposição a estar em constante atualização ou aprimoramento, de modo a ampliar seu aprendizado, agregando novos conhecimentos e experiências, a fim de qualificar sua prática pedagógica.

A investigação revelou que, através das partilhas, as quais consideraram a diversidade dos contextos dos participantes em formação, os formadores fomentaram trocas, reflexões, diferentes vivências, novos conhecimentos, compartilhamento das angústias e superação de desafios, além de construções essenciais ao processo formativo coletivo realizado no contexto investigado.

Ficou evidente que os professores buscaram nos processos formativos a inovação para as aulas, destacando a relação entre teoria e prática presente em tais processos. Dito de modo mais pormenorizado, buscaram a incorporação de algo novo à sua prática, seja um conceito, uma metodologia ou um novo jogo para desenvolver e trabalhar determinado tema da área de $\mathrm{EF}$, além da possibilidade de novas e diversificadas experiências capazes de impactar no processo de ensino e aprendizagem.

A formação continuada foi sinalizada como espaço e tempo para o professor reexaminar e revisitar sua própria prática pedagógica, de modo a analisar suas ações com o propósito de instaurar um processo reflexivo, valorizando as ações desenvolvidas no cotidiano escolar, a partir da visualização das práticas positivas presentes nas suas aulas, projetando novas possibilidades de ação que sejam significativas no desenvolvimento e na formação integral dos alunos.

Evidenciamos a importância da formação continuada para a inovação e a qualificação da prática do professor. Cabe, porém, ressaltar que essa mudança em seu fazer pedagógico não acontece de imediato, que é preciso uma reflexão sobre e a partir de suas aulas, para que seja possível uma reorganização, uma reconstrução do que o professor desenvolve no ambiente escolar.

Esse estudo limitou-se a apresentar e discutir as relações existentes no âmbito dos processos formativos realizados pela SMEd, os quais, de acordo com os professores investigados, contribuíram diretamente em suas pratica pedagógica. Salientamos que a intencionalidade das ações formativas associada ao momento especial de apropriação da BNCC propiciou a participação ativa dos professores de EF na construção de saberes coletivos, refletidos no DOCTR no município do Rio Grande/RS.

Por fim, sugerimos a realização de novas investigações referentes à implementação do DOCTR, assim como à identificação dos impactos ocorridos na pratica pedagógica dos professores no cotidiano escolar e o reflexo na aprendizagem dos alunos. 


\section{REFERENCIAS}

AZEVEDO, Andréa Maria Pires; OLIVEIRA, Glycia Melo; SILVA, Priscilla Pinto Costa; NÓBREGA, Thereza Karolina Sarmento; SOUZA JÚNIOR, Marcílio. Formação continuada na prática pedagógica: a Educação Física em questão. Revista Movimento, Porto Alegre, v. 16, n. 04, p. 245-262, out./dez. 2010. Disponível em: https://seer.ufrgs.br/Movimento/article/view/11809 . Acesso em: 20 jun. 2020.

BAGATINI, Gabriela Zucki; SOUZA, Maristela da Silva. Formação continuada para professores de Educação Física: análise da produção do conhecimento. Revista Motrivivência, Florianópolis, v. 31, n. 58, p. 01-16, 2019. Disponível em:

https://periodicos.ufsc.br/index.php/motrivivencia/article/view/2175-8042.2019e55279/40210. Acesso em: 01 set. 2020.

BAHIA, Cristiano de Sant Anna. Formação continuada em exercício de professores da Educação Física escolar: contribuições para a prática pedagógica. 2016. 194 f. Tese (Doutorado em Educação Física) Programa de Pós-Graduação em Educação Física da Universidade Federal de Santa Catarina. Florianópolis: UFSC, 2016.

BARDIN, Laurence. Análise de conteúdo. Tradução de Luiz Antero Reto e Augusto Pinheiro. São Paulo: Edições 70, 2016.

BORGES, Simoni Pereira; CARVALHO, Edione Teixeira de. O papel do formador no processo de formação continuada: formadores ou informadores. Research, Society and Development, Itabira, v. 9, n. 3, p. 01-18, 2020. Disponível em: https://www.researchgate.net/publication/338424351. Acesso em: 20 jun. 2020.

BRASIL. Congresso Nacional. Lei n. 9.394, de 20 de dezembro de 1996. Estabelece as diretrizes e bases da educação nacional. Diário Oficial da União, Brasília, DF, 23 dez. 1996.

BRASIL. Resolução CNE/CP N 2 de 20 de dezembro de 2017. Institui e orienta a implantação da Base Nacional Comum Curricular, a ser respeitada obrigatoriamente ao longo das etapas e respectivas modalidades no âmbito da Educação Básica. Brasília: CNE/CP, 2017.

FALKEMBACH, Elza Maria Fonseca. Diário de campo: um instrumento de reflexão. Revista Contexto e Educação. Ijuí, RS, v. 2, n. 7, p. 19-24, 1987.

GODOI, Marcos; BORGES, Cecília. A percepção dos professores sobre o currículo de Educação Física e a formação continuada em Cuiabá-MT, Brasil. Revista Currículo sem Fronteiras, [s.1.], v. 19, n. 1, p. 379-395, jan./abr. 2019. Disponível em:

https://www.curriculosemfronteiras.org/vol19iss1articles/godoi-borges.pdf. Acesso em: 20 jun. 2020.

GIL, Antônio Carlos. Como elaborar projetos de pesquisa. 4. ed. São Paulo: Atlas, 2008.

NÓVOA, António. Formação de professores e profissão docente. In: NÓVOA, António (Org.). Os professores e a sua formação. Lisboa: Dom Quixote, 1995. p. 15-34.

OLIVEIRA, Fabyana Soares. Formação continuada em Educação Física: desafios e possibilidades com alunos que apresentam deficiência na escola regular. 2020. 148 f. Dissertação (Mestrado em Educação). Programa de Pós-graduação em Educação da Universidade Federal do Rio Grande do Norte. Natal: UFRN, 2020.

RIGH, Marisa; MARIN, Elizara Carolina; SOUZA, Maristela da Silva. Formação continuada: entendimentos e vivências dos professores de Educação Física no contexto do governo estadual (RS) gestão 2007/2010.

Revista Brasileira de Ciências do Esporte, Florianópolis, v. 34, n. 4, p. 875-890, out./dez., 2012.

Disponível em: 
https://www.scielo.br/scielo.php?pid=S0101-32892012000400006\&script=sci abstract\&tlng=pt. Acesso em: 20 jun. 2020.

RIO GRANDE. Lei no 7848/2015. Altera a redação dos $\operatorname{artigos~} 5^{\mathbf{0}}, \mathbf{6}^{\mathbf{0}}, \mathbf{7}^{\mathbf{0}}$ e $\mathbf{8}^{\mathbf{0}}$ da lei 5.336/1999. Rio Grande, 2015.

RS - RIO GRANDE DO SUL. Resolução n ${ }^{\circ}$ 345, de 12 de dezembro de 2018. Institui e orienta a implementação do Referencial Curricular Gaúcho - RCG. Conselho Estadual de Educação do Rio Grande do Sul, 2018.

ROSSI, Fernanda. Implicações da formação continuada na prática pedagógica do(a) professor(a) no âmbito da cultura corporal do movimento. 2013. 286 f. Tese (Doutorado em Ciências da Motricidade) Instituto de Biociências da Universidade Estadual Paulista Júlio de Mesquita Filho. Rio Claro: UNESP, 2013a.

ROSSI, Fernanda. A formação continuada sob análise do professor escolar. São Paulo: Editora Unesp, $2013 b$.

ROSSI, Fernanda; HUNGER, Dagmar. A formação continuada de professores: entre o "real" e o "ideal". Revista Pensar a Prática, Goiânia, v. 15, n. 4, p. 821-1113, out./dez. 2012a. Disponível em: https://www.revistas.ufg.br/fef/article/view/15564. Acesso em: 20 jun. 2020.

ROSSI, Fernanda; HUNGER, Dagmar. As etapas da carreira docente e o processo de formação continuada de professores de Educação Física. Revista Brasileira de Educação Física e Esporte, São Paulo, v. 26, n. 2, p. 323-38, abr./jun. 2012b. Disponível em:

https://www.scielo.br/scielo.php?pid=S1807-55092012000200014\&script=sci abstract\&tlng=pt . Acesso em: 20 jun. 2020.

SILVA, Elifas Levi; PACCA, Jesuina Lopes de Almeida. Algumas implicações do trabalho coletivo na formação continuada de professores. Revista Ensaio, Belo Horizonte, v. 13, n. 03, p. 31-49, set./dez. 2011. Disponível em:

https://www.scielo.br/scielo.php?pid=S1983-21172011000300031\&script=sci abstract\&tlng=pt. Acesso em: 20 jun. 2020.

SILVA, Patrícia da Rosa Louzada da; MONTIEL, Fabiana Celente; ROSSETTO JÚNIOR, Adriano José; PINHEIRO, Eraldo dos Santos. Formação continuada de professores e a aplicação dos princípios pedagógicos do esporte educacional. Revista Humanidades e Inovação, Palmas, v. 7, n. 10, p. 169-185, 2020. Disponível em: https://revista.unitins.br/index.php/humanidadeseinovacao/article/view/2352. Acesso em: 20 jun. 2020.

\section{NOTAS DE AUTOR}

AGRADECIMENTOS - Não se aplica.

CONTRIBUIÇÃO DE AUTORIA - Não se aplica.

FINANCIAMENTO - Não se aplica.

CONSENTIMENTO DE USO DE IMAGEM - Não se aplica. 


\section{APROVAÇÃO DE COMITÊ DE ÉTICA EM PESQUISA}

O estudo foi aprovado pelo Comitê de Ética em Pesquisa da Escola Superior de Educação Física da Universidade Federal de Pelotas /RS, através do parecer nº 3.401.631 de 19 de junho de 2019.

CONFLITO DE INTERESSES - Não há conflito de interesses.

\section{LICENÇA DE USO}

Os autores cedem à Motrivivência - ISSN 2175-8042 os direitos exclusivos de primeira publicação, com o trabalho simultaneamente licenciado sob a Licença Creative Commons Attribution Non-Comercial ShareAlike (CC BY-NC SA) 4.0 International. Esta licença permite que terceiros remixem, adaptem e criem a partir do trabalho publicado, desde que para fins não comerciais, atribuindo o devido crédito de autoria e publicação inicial neste periódico desde que adotem a mesma licença, compartilhar igual. Os autores têm autorização para assumir contratos adicionais separadamente, para distribuição não exclusiva da versão do trabalho publicada neste periódico (ex.: publicar em repositório institucional, em site pessoal, publicar uma tradução, ou como capítulo de livro), com reconhecimento de autoria e publicação inicial neste periódico, desde que para fins não comerciais e compartilhar com a mesma licença.

\section{PUBLISHER}

Universidade Federal de Santa Catarina. Programa de Pós-Graduação em Educação Física. LaboMídia - Laboratório e Observatório da Mídia Esportiva. Publicado no Portal de Periódicos UFSC. As ideias expressadas neste artigo são de responsabilidade de seus autores, não representando, necessariamente, a opinião dos editores ou da universidade.

\section{EDITORES}

Mauricio Roberto da Silva, Giovani De Lorenzi Pires, Rogério Santos Pereira.

\section{EDITOR DE SEÇÃO}

Juliano Silveira.

\section{REVISÃO DO MANUSCRITO E METADADOS}

João Caetano Prates Rocha; Keli Barreto.

\section{HISTÓRICO}

Recebido em: 09 de setembro de 2020.

Aprovado em: 07 de dezembro de 2020. 